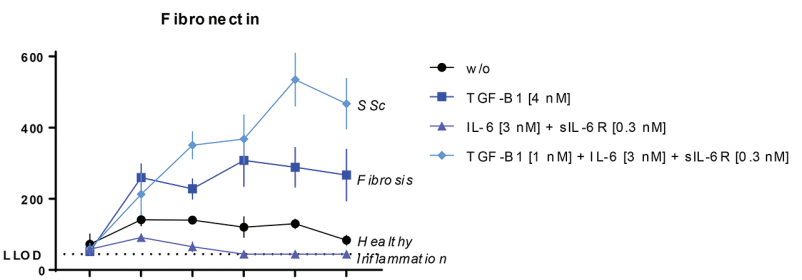

Time [Days]

Abstract THU0335 - Figure 2

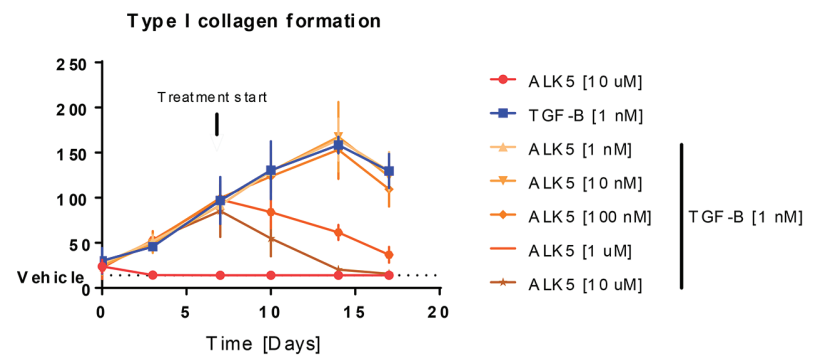

Abstract THU0335 - Figure 3

Stimulation with IL-6 decreased fibronectin levels compared to w/o, whereas TGF- $\beta$ increased this. A combination of both cytokines resulted in a further increase in fibronectin levels (IL-6: $44 \mathrm{ng} / \mathrm{ml}$, TGF- $\beta$ : $308 \mathrm{ng} /$ $\mathrm{ml}, \quad$ IL-6+TGF- $\beta$ : $368 \mathrm{ng} / \mathrm{ml}, \quad \mathrm{P}<0.0001$ ) (Figure 2). Treatment with iALK-5 $(\geq 1 \mu \mathrm{M})$ decreased type I collagen formation levels to those of the vehicle, while $100 \mathrm{nM}$ showed a tendency to be lower (TGF- $\beta$ : $129 \mathrm{ng}$ / $\mathrm{ml}$, TGF- $\beta+100 \mathrm{nM}$ iALK-5: $94 \mathrm{ng} / \mathrm{ml}$, not significant). IALK-5 at $1 \mu \mathrm{M}$ or above, could rescue cells after 7 days pretreatment with 1 nM TGF- $\beta$ (TGF- $\beta$ : $129 \mathrm{ng} / \mathrm{ml}$, TGF- $\beta+1 \mu \mathrm{M}$ iALK-5: $37 \mathrm{ng} / \mathrm{ml}$, TGF- $\beta+10 \mu \mathrm{M}$ iALK-5: $14 \mathrm{ng} / \mathrm{ml}$ ). Levels were decreased from day 10 (Figure 3 ).

Conclusion: TGF- $\beta$ and PDGF induced very different ECM compositions, with PDGF inducing much more type $\mathrm{VI}$ collagen formation as compared to TGF- $\beta$. In contract, TGF- $\beta$ induce a highly type I collage dependent ECM. This model system and biomarkers may be used to test novel anti-fibrotic compounds, and allow for identification of patient with the endotype of fibrosis that may responds the best to treatment.

Disclosure of Interests: Pernille Juhl: None declared, Sandie Bomdesen: None declared, Anne-Christine Bay-Jensen Shareholder of: I own shares of Nordic Bioscience, Employee of: I am a full-time employee in Nordic Bioscience, Morten Karsdal Shareholder of: I own shares of Nordic Bioscience, Employee of: I am a full-time employee in Nordic Bioscience, Michael Jonathan Davies: None declared, Anne Sofie Siebuhr Employee of: I am a full-time employee in Nordic Bioscience

DOI: 10.1136/annrheumdis-2019-eular.5477

\section{THU0336 DEVELOPING A NOVEL RAPID EX VIVO MODEL OF SKIN FIBROSIS FOR SYSTEMIC SCLEROSIS RESEARCH}

Liyoung Kim ${ }^{1}$, Madhavi Latha Somaraju ${ }^{2}$, Tania Pannellini ${ }^{2}$, Theresa Lu ${ }^{1} .{ }^{1}$ Hospital for Special Surgery, Main Campus, Pediatric Rheumatology, New York, United States of America; ${ }^{2}$ Hospital for Special Surgery, Main Campus, New York, United States of America

Background: Systemic Sclerosis (SSc) is an autoimmune disease that causes tissue fibrosis in multiple systems. Immune dysfunction and dysregulation are known to play a role in the disease, but the pathophysiology of SSc is not clearly understood.(1) Adipose-derived stromal cells (ADSCs) reside in the dermal white adipose tissue (DWAT) and have reparative and regenerative functions.(2) We have previously shown that ADSCs are lost in SSc and that injecting these along with a survival signal can partially reverse fibrosis.(3) To better understand how ADSCs reverse fibrosis, we wanted to develop an ex vivo skin fibrosis model. As the commonly used in vivo bleomycin-injected fibrosis model takes three to four weeks to prepare, a more rapid ex vivo model would further facilitate mechanistic dissection.
Objectives: This pilot study aims to establish a novel ex vivo experimental model that can demonstrate fibrotic change in mouse skin and represent ADSC loss within days rather than within weeks needed for current models. Methods: Six B6 mice were sacrificed at between 12-16 weeks of age and skin tissues were obtained from the back by $8 \mathrm{~mm}$ punch biopsies. Skin samples were immersed in Dulbecco's Modified Eagle's Medium containing either bleomycin (5 or $10 \mathrm{mU} / \mathrm{ml}$ ) or PBS as control for one or three days. After harvesting, H\&E staining was performed on skin sam ples to assess phenotypic fibrotic changes. Flow cytometry (FACS Canto) was used to measure the viability, total cell number and ADSC change A total collagen assay quantified collagen production in samples.

Results: On H\&E staining, compared to controls, samples cultured with $5 \mathrm{mU} / \mathrm{ml}$ bleomycin for a day showed increased density of dermis and deposition of amorphous pink material, likely representing increased collagen. With $10 \mathrm{mU} / \mathrm{ml}$ bleomycin, these changes were greater and especially affected the upper dermis. On day 3 , samples in $5 \mathrm{mU} / \mathrm{ml}$ and $10 \mathrm{mU} / \mathrm{ml}$ bleomycin appeared to have denser fibrosis, broader dermis band, and narrower DWAT layer. The histopathological change was most prominent on day 3 sample in $10 \mathrm{mU} / \mathrm{ml}$ bleomycin, with the dermis layer $40 \%$ thicker and the DWAT layer 37\% narrower than the control. However, all the samples on day 3 showed stress, such as epidermis detachment and apoptosis in the epidermis. On the Total Collagen Assay, collagen deposition on day 1 in control sample was $7.7 \mathrm{ug} / \mathrm{mm}$, compared to $33.9 \mathrm{ug} / \mathrm{mm}$ from sample in $10 \mathrm{mU} / \mathrm{ml}$ bleomycin. On day 3 , collagen deposition in $10 \mathrm{mU} / \mathrm{ml}$ bleomycin was $37 \mathrm{ug} / \mathrm{mm}$ which was 2.5 to 5 times higher than control. On FACS, the decrease in ADSC level correlated to the increase in concentration of bleomycin and the number of days treated, with the greatest drop in samples in $10 \mathrm{mU} / \mathrm{ml}$ bleomycin on day 3 .

Conclusion: Our results thus far suggest that we are creating a novel ex vivo model of skin fibrosis that can help better understand how ADSCs can be of therapeutic benefit in SSc. This rapid ex vivo model will complement the existing in vivo model. Our next step will be to investigate the changes of profibrotic cytokines before and after applying ADSCs purified from healthy mice to understand how skin fibrosis can be reversed.

\section{REFERENCES:}

[1] Gilbane, Adrian J et al. "Scleroderma pathogenesis: a pivotal role for fibro blasts as effector cells" Arthritis research \& therapy vol. 15,3 (2013): 215

[2] Marangoni, Roberta G.; Lu, Theresa T. "The roles of dermal white adipose tissue loss in scleroderma skin fibrosis" Current Opinion in Rheumatology vol 29(6), (2017): 585-590

[3] Chia, Jennifer $J$ et al. "Dendritic cells maintain dermal adipose-derived stromal cells in skin fibrosis" Journal of clinical investigation vol. 126,11 (2016): 4331-4345
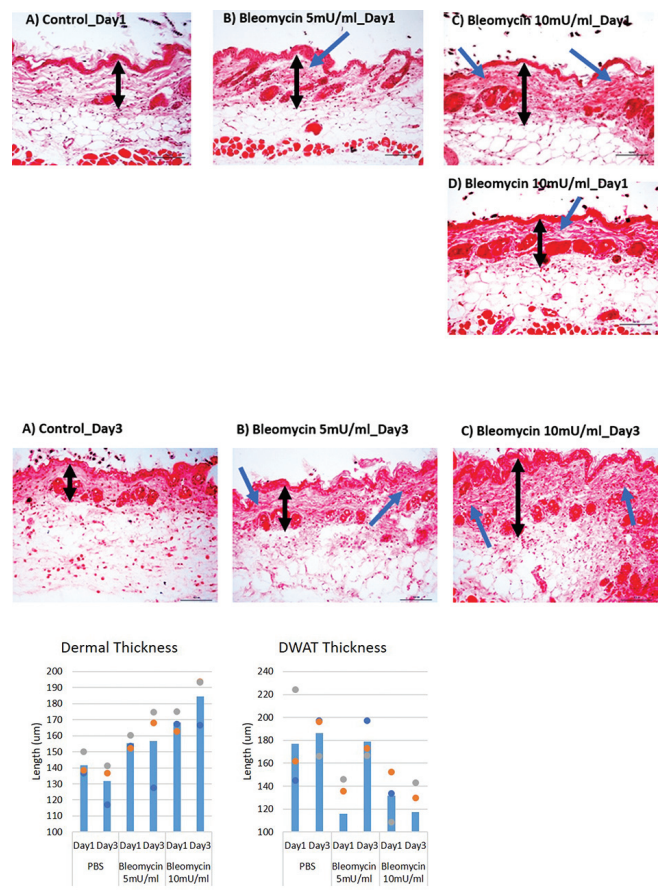

Abstract THU0356 - Figure 1. H\&E. Blue arrows showed the areas where there are increased collagen deposition and density. 


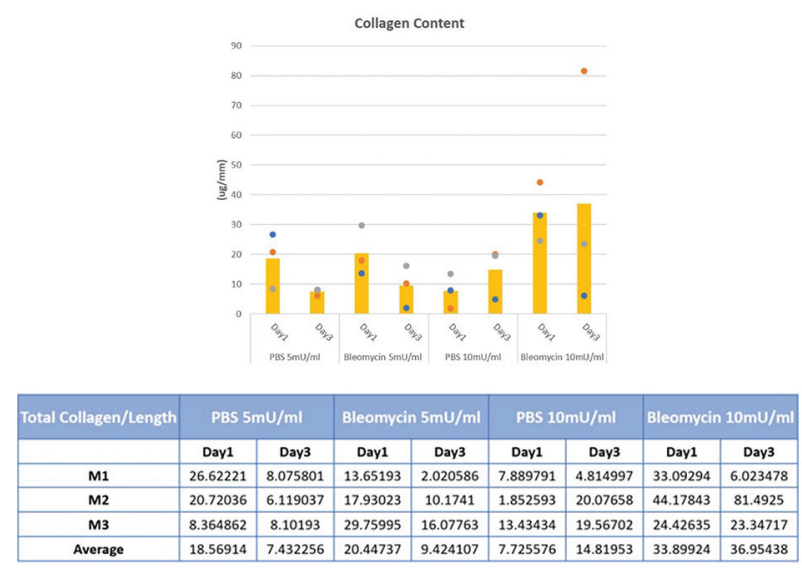

Abstract THU0356 - Figure 2. Total collagen content

ADSC Absolute Cell Count on Day1
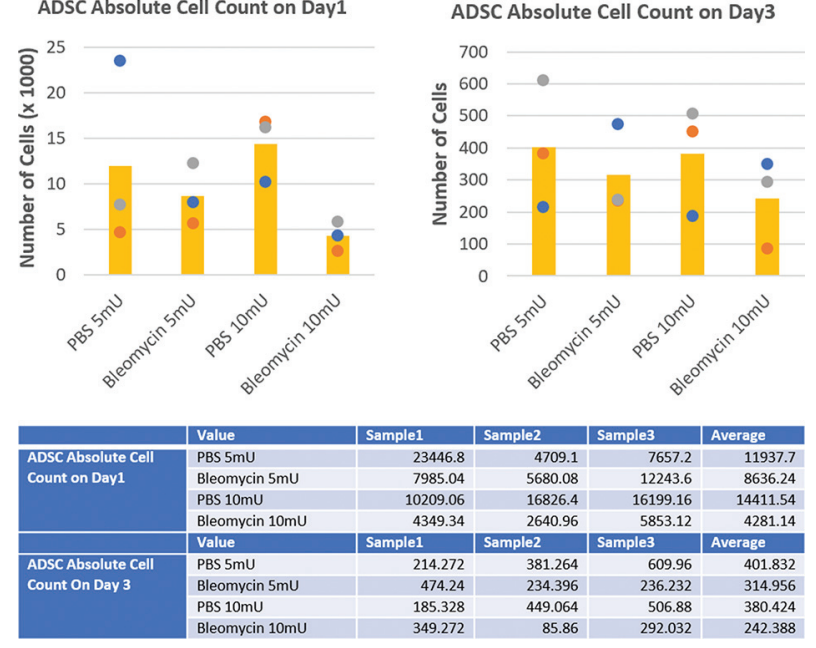

\begin{tabular}{|c|c|c|c|}
\hline & samplez & Samplez & erag: \\
\hline 23446.8 & 4709.1 & 7657.2 & 11937.7 \\
\hline 7985.04 & 5680.08 & 12243.6 & 8636.24 \\
\hline 10209.06 & 16826.4 & 16199.16 & 14411.54 \\
\hline 4349.34 & 2640.96 & 5853.12 & 4281.14 \\
\hline le1 & Sample2 & Sample3 & Average \\
\hline 214.272 & 381.264 & 609.96 & 401.832 \\
\hline 474.24 & 234.396 & 236.232 & 314.956 \\
\hline 185.328 & 449.064 & 506.88 & 380.424 \\
\hline 349.272 & 85.86 & 292.032 & 242.388 \\
\hline
\end{tabular}

Abstract THU0356 - Figure 3. ADSC cell count measured by flow cytometry

Disclosure of Interests: None declared

DOI: 10.1136/annrheumdis-2019-eular.1881

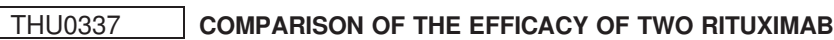 REGIMENS IN THE PATIENTS WITH SYSTEMIC SCLEROSIS ASSOCIATED WITH INTERSTITIAL LUNG DISEASE}

Olga Koneva, Lidia P. Ananyeva, Liudmila Garzanova, Oxana Desinova, Olga Ovsyannikova, Mayya Starovoytova. V.A. Nasonova Research Institute of Rheumatology, Moscow, Russian Federation

Background: Rituximab (RTM) is considered as a promising therapeutic agent for treatment of insterstitial lung disease (ILD) in the patients with systemic sclerosis (SSc). However, the limited number of RTM-treated patients, heterogeneity of the studies in relation to main parameters, considerably different dose regimens, cumulative doses, and observation periods does not allow univocal conclusions on RTM efficacy or definitive recommendations on RTM use in the patients with SSc. The question whether to combine RTM with immunosupressants (IS) or it is possible to use it as a single-agent therapy in the patients with SSc associated with ILD is still relevant.

Objectives: To compare the time courses of pulmonary function parameters and dermal fibrosis parameters during the use of RTM in combination with IS and as a single-agent therapy in the patients with SSc associated with ILD in the open-label prospective non-randomized study. Methods: 90 patients with the confirmed SSc diagnosis and ILD evidence based on HRCT findings were enrolled into the study. All patients received low-dose and moderate-dose prednisolone regimens. Group A $(\mathrm{n}=45)$ received a total $\mathrm{RTM}$ dose $3.1 \pm 1.2 \mathrm{~g}$ in combination with IS
(27/60\% mycophenolate mofetyl, 16/35.6\% cyclophosphamide, 2/4.4\% methotrexate; the patient's average age was $47.4 \pm 11.6$ years, with female proportion $82 \%$; SSc duration $4.6 \pm 3.5$ years; diffused/localized forms $1.3 /$ 1). Group B $(n=45)$ received $R T M$ as a single therapy agent in a total dose $2.7 \pm 1 \mathrm{~g}$ (average age $45.0 \pm 15$ years, female proportion $82 \%$, SSc duration $6.7 \pm 5.6$ years, diffused/localized forms 1.5/1). The age, gender proportion, SSc form, FVC and DLCO, and RTM cumulative doses were similar in the both groups. The follow-up period was 42 months. The time courses of FVC, DLCO, modified skin count (mRss, points), activity index (EScSG, points) were assessed in the study.

Results: In Groups A and B during the therapy significant decrease in mRss ( $p=0.00034$ and 0.000002 respectively) and EScSG $(p=0.00011$ and 0.000000 respectively), FVC increase $(p ;=0.00017$ and 0.00001 , respectively), and stabilization of the DLCO were observed.

The treatment groups did not differ significantly in the median FVC increment, clinically meaningful FVC and DLCO increments of decrements, and EScSG and mRss time courses.

\begin{tabular}{lcc}
\hline Parameters & Group A & Group B \\
\hline EScSG 1 & $3.2 \pm 1.9^{*}$ & $2.7 \pm 1.6^{*}$ \\
$M \pm S D$ & $1.6 \pm 1.3^{*}$ & \\
EScSG 2 & & $1.2 \pm 0.98^{*}$ \\
$M \pm S D$ & $11.0 \pm 9.3^{*}$ & \\
mRss 1 & & $11.5 \pm 9.3^{*}$ \\
$M \pm S D$ & $7.2 \pm 5.6^{*}$ & \\
mRss 2 & & $5.6 \pm 4.2^{*}$ \\
$M \pm S D$ & $76 \pm 20.3^{*}$ & \\
FVC $1 M \pm S D$ & $82.7 \pm 22.5^{*}$ & $77.8 \pm 19.7$ \\
FVC $2 M \pm S D$ & 5.7 & $86.8 \pm 19.7^{*}$ \\
$\Delta$ FVC $\%$ & {$[0 ; 11.2]$} & 8.3 \\
& $14 / 31$ & {$[1.1 ; 15.4]$} \\
FVC increment by $\geq 10 \%, \mathrm{n} / \%$ & $2 / 4.4$ & $17 / 37.8$ \\
FVC decrement by $\geq 10 \% \mathrm{n} / \%$ & $44.5 \pm 19$ & $2 / 4.4$ \\
DLCO $1 M \pm S D$ & $45.4 \pm 16.8$ & $47.8 \pm 17.1$ \\
DLCO $2 M \pm S D$ & 1.3 & $50.4 \pm 16.9$ \\
$\Delta$ DLCO $\%$ & {$[-1.6 ; 6.9]$} & 2.1 \\
DLCO increment by $\geq 10 \%, \mathrm{n} / \%$ & $3 / 6.7$ & {$[-1.41 ; 7.1]$} \\
DLCO decrement by $\geq 10 \% \mathrm{n} / \%$ & $5 / 11$ & $5 / 11$ \\
\end{tabular}

Notes: in Parameters column 1 = before treatment, 2 = after treatment; $M \pm S D=$ mean value and standard deviation; * significant difference between the vales measured before and after the treatment

Conclusion: RTM administration both in combination with IS and as a single agent therapy in the patients with SSc associated with ILD effectively alleviated skin induration and EScSG, improved or stabilized the pulmonary function parameters. The absence of statistically significant difference in the time course of evaluated parameters between the groups substantiate potential RTM use as a single-agent therapy that, this is most important for the patients with poor tolerability or contraindications to IS administration.

Disclosure of Interests: None declared

DOI: 10.1136/annrheumdis-2019-eular.6870

\section{THU0338 SIMVASTATIN-CONJUGATED NANOPARTICLE ENHANCES THE THERAPEUTIC EFFECT OF ADIPOSE- DERIVED STEM CELLS ON INTERSTITIAL LUNG DISEASE}

Takuya Kotani, Takayasu Suzuka, Shogo Matsuda, II Masaaki, Tohru Takeuchi, Shigeki Arawaka. Osaka Medical College, Takatsuki, Japan

Background: Interstitial lung disease (ILD) associated with connective tis sue disease is a life-threatening pathological condition that causes respiratory failure when it progresses. Lung inflammation is treated with corticosteroids and immunosuppressants, and pulmonary fibrosis is treated with anti-fibrosis agents such as pirfenidone and nintedanib. However, many cases are treatment-resistant and the outcome is poor. Moreover adverse effects such as infections resulting from immunosuppressive therapy are problematic. The development of new treatments is thus required for ILD from the viewpoint of the poor effect and adverse effects of the currently available treatments. Research and development with adiposederived stem cells (AdSCs) in immunosuppressive therapy have progressed for autoimmune diseases, and favorable outcomes have been reported. In recent years, the effectiveness of AdSCs in ILD model mice has been demonstrated (ref). The statin preparation has not only an angiogenesis promoting action, an immunosuppressive action, an antifibrotic action but also an action of promoting a cellular function including a migratory ability. 